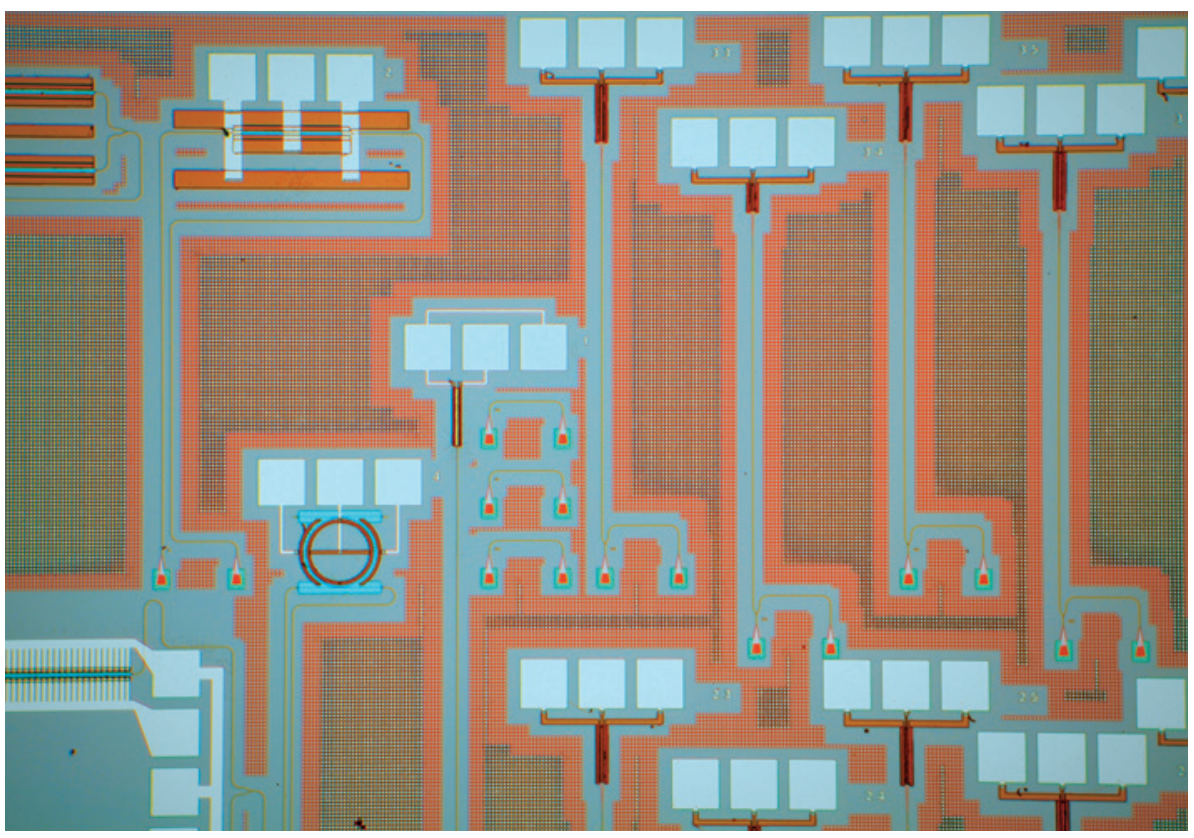

Optical components including modulators, waveguides and photodetectors crowd a silicon chip.

TECHNOLOGY

\title{
Photonic chips made easier
}

\section{Shared-production system aids academics and start-ups.}

\section{BY KATHERINE BOURZAC}

$\mathrm{I}$ f you want to speed up computers much more, you will need a faster messenger. That is the idea behind silicon photonics, which whizzes data around a silicon chip using light instead of sluggish old electrons.

Photons already carry data in fibre-optic cables for telecommunications. But using light in computing means carving transistors and lasers out of the same wafer of silicon, which needs an advanced manufacturing 'foundry'. Only large companies and a few research institutions with deep pockets have these facilities, and some researchers worry that lack of access is slowing progress in photonics.

A project called Optoelectronic Systems Integration in Silicon (OpSIS) now promises a solution. Based at the University of Washington in Seattle and at the University of Delaware in Newark, OpSIS provides design support for researchers in silicon photonics; organizes shared production runs; and arranges low-cost access to advanced foundries so that academics and start-up companies can create prototype devices. The US Air Force is the project's biggest funder, with more support coming from Intel, based in Santa Clara, California,

and design-automation company Mentor Graphics in Wilsonville, Oregon.

OpSIS will make its first batch of silicon photonics prototype chips at the Institute of Microelectronics' foundry in Singapore this month. Its customers are some 25 groups working on high-speed communications circuits, portable medical diagnostic devices and photonics basic research.

Users will pay US $\$ 1,500$ for one square millimetre of wafer space, with projects requiring anywhere from $10 \mathrm{~mm}^{2}$ to $40 \mathrm{~mm}^{2}$. Researchers going it alone would have to pay for a complete production run at the foundry - at a cost many times higher. OpSIS offers much lower prices by putting many different projects into a single run and splitting the cost.

Michael Hochberg, a photonics researcher at the University of Delaware who co-founded and leads OpSIS, knows how expensive it can be to translate silicon photonics technology from university lab into product. In 2001, he co-founded

\section{$\rightarrow$ NATURE.COM}

For more on silicon photonics, see

Focus at:

go.nature.com/yqwdaa
Luxtera, in Carlsbad, California, the first company to offer integrated electronics and optics on chips, which are now used commercially in data centres and supercomputers. Luxtera spent more than $\$ 100$ million to develop and produce its first product, released in 2010. "I want to $z$ make it possible to do what Luxtera did for an order of magnitude less cost," says Hochberg. OpSIS will soon also have access to foundries owned by Luxtera and by UK aerospace company BAE Systems, headquartered in London.

The history of the silicon chip suggests that OpSIS could be hugely influential. Its sharedproduction model is based on the University of Southern California's Metal Oxide Semiconductor Implementation Service (MOSIS), which has been operating since 1981 in Marina del Rey and has helped the semiconductor industry to grow rapidly. Electronics pioneers, including Carver Mead at the California Institute of Technology in Pasadena, pushed for academics and small companies to gain access to fabrication facilities ('fabs') to build the integrated circuits they needed to test their ideas and train students. At the time, academics were restricted to making simple devices in the lab, doing theoretical work or - as Mead did - having friends at Intel sneak their students' designs into production runs. "You have to have access to a fab to build the real thing," says Mead.

Silicon photonics now is at a similar stage to the electronics industry in the early 1980 s, says Mario Paniccia, director of the photonics technology lab at Intel. Today's photonics researchers have better access to foundries than Mead did decades ago, but most are still excluded from the cutting-edge facilities that can make more complicated devices.

A data-processing photonic chip, for example, must integrate lasers, waveguides and electrical transistors in complex systems that are completely reliable. Making such devices in advanced fabrication facilities ensures that they are of acceptable quality, says OpSIS user S. J. Ben Yoo, director of the Center for Information Technology Research in the Interest of Society at the University of California in Davis.

A service similar to OpSIS has been offered since 2008 by the ePIXfab initiative, funded in part by the European Union. But OpSIS has access to more advanced foundries, says Lukas Chrostowski, an electrical engineer at the University of British Columbia in Vancouver, Canada.

Chrostowski has 20 designs in the first OpSIS run. Several are prototype versions of optical sensors for a hand-held medical-diagnostic device that could analyse blood samples to detect disease biomarkers. Previous versions of this system were far from being hand-held: Chrostowski had to attach an external laser and a detector to an optical chip he made using ePIXfab. Through OpSIS, he will now be able to integrate all the building blocks onto one chip in a more realistic prototype.

This sort of innovation cannot be left only to well funded companies, says Paniccia. "We need more people experimenting, learning, and innovating with silicon photonics." - 